\title{
Primary Characterization of the Volatile Profile of Port Salut Argentino Light Cheese with the Addition of Milk Protein Concentrate by HS-SPME/GC-MS
}

\author{
Ivana Cecilia Alberini ${ }^{1,2}$, Amelia Catalina Rubiolo \\ ${ }^{1}$ Research Lab LIRA, School of Science of Alimentation, National University of Entre Ríos, Monseñor Tavella, Concordia, Argentina \\ ${ }^{2}$ Group of Food Engineering and Biotechnology, INTEC - PTLC, Colectora Ruta Nacional 168, Santa Fe, Argentina
}

Email address:

ialberini@intec.unl.edu.ar (I. C. Alberini), arubiolo@intec.unl.edu.ar (A. C. Rubiolo)

\section{To cite this article:}

Ivana Cecilia Alberini, Amelia Catalina Rubiolo. Primary Characterization of the Volatile Profile of Port Salut Argentino Light Cheese with the Addition of Milk Protein Concentrate by HS-SPME/GC-MS. Journal of Food and Nutrition Sciences. Vol. 4, No. 5, 2016 , pp. $120-125$. doi: $10.11648 /$ j.jfns.20160405.11

Received: June 12, 2016; Accepted: June 13, 2016; Published: August 15, 2016

\begin{abstract}
Port Salut Argentino light cheese is a typical variety of soft cheese produced in Argentina made with cow milk, and in this work has the addition of milk protein concentrate (MPC). Aroma and flavor are the most important food quality criteria, in fact it is generally accepted that the volatile profile reflects the image of the smelting and aroma of cheeses. To characterize the profile of volatile compounds, gas chromatography coupled to mass spectrometry is the used method, and the isolation of compounds from cheese matrix, was using headspace solid phase micro-extraction. The methodology allowed the determination of 24 volatile compounds in the Port Salut Argentino Light with MPC at 34 days of maturation: six fatty acids, six ketones, five alcohols, three esters, one aldehyde, two aromatics and one sulphur compound. Some of the metabolic pathways for their biosynthesis are reviewed to indicate the possible origin of the compounds identified.
\end{abstract}

Keywords: Port Salut Argentine Cheese, Volatile Compounds, HS-SPME/GC-MS

\section{Introduction}

This aroma and flavour are the most important food quality criteria. They are major attributes that influence the selection and consumption of food. The acceptability of cheese by consumers mainly depends on its sensory qualities and in this context, flavour is determinant. It is generally accepted that the volatile profile reflects the image of the odour and aroma of cheeses [1].

The study of flavor is useful to linking it with the area and the methodology of production. Several studies have been performed to characterize the volatile fraction to the most common and well-known varieties of cheeses, e.g. Emmental, Cheddar, Camembert, Reggianito Argentino and Parmiggiano [2].

The principal flavour compounds in cheese are derived from carbohydrate (mainly lactose), citrate, protein (mainly casein) and milk fat, as a result of glycolysis, citrate fermentation, proteolysis and lipolysis by microorganisms, respectively; mainly due to enzymes from milk, rennet and microorganisms and/or non enzymatic reactions that contribute to proteolysis and lipolysis [3].

Lipolysis is the principal reaction in the development of flavour in a range of cheeses. It is caused by an indigenous milk lipase, by exogenously added mammalian pregastric esterase-lipases and/or by microbial lipases (exogenously added or derived from microorganisms). In summary, the major flavor compounds that are released during lipolysis are free fatty acids (FFAs), which directly affect cheese flavor FFAs can be transformed by microorganisms to other, and often, more potent flavour compounds, including methyl ketones, lactones, esters, secondary alcohols and aldehydes, which also directly affect flavour in different cheeses [3].

To characterize the volatile compounds of a cheese, gas chromatography (GC) coupled to mass spectrometry (MS) is the preferred method, where the volatile identification is usually achieved by library search based on the comparison of the experimental mass spectra with those stored in a suitable library (e. g. via the National Institute of Standards and Technologies, NIST) [1]. 
The isolation of compounds from cheese matrix requires a prior step involving the extraction and pre-concentration of the volatile fraction. Solid phase microextraction (SPME) is an analytical technique that integrates sampling, extraction and concentration of volatile or nonvolatile compounds from matrices both in the solid and liquid states in a short time, in a simple way [1]. This technique fits the conditions required for quality control analysis in the dairy industry because it is cheap, easy to use, and relatively fast to execute.

Headspace solid phase microextraction (HS-SPME) has been found preferable to other techniques, because it is solvent free, and presents high sensitivity and limited risk of artifacts [4]. The principle of headspace SPME is an equilibrium partitioning of analytes among the coating of solid phase or fiber, sample matrix, and/or headspace. The traditional and widely used polydimethylsiloxane fiber coating has very good stability and is usually the first fiber tested; this fiber has very sensitivity to non polar compounds, but not to polar compounds.

With the intent of providing product identity for legal, economic and manufacturing purposes, several studies have been conducted to define the proximate composition, starter, ripening and manufacturing protocol for Port Salut Argentino light cheese with the addition of milk protein concentrate (MPC) made with cow milk.

Milk protein concentrate (MPC) is a substance obtained by the removal of non-protein constituents from pasteurized skim milk, so that the final product has a percentage of protein higher than $38 \%$. Due to protein and lactose levels are related, as much the protein content is, less the lactose content is. The main features of this product are low lactose concentration, high content of calcium, excellent thermal and emulsion stability, besides the high nutritional value and its functionality. The MPC can be produced by physical methods such as precipitation, filtration (ultrafiltration) and dialysis. MPC is used in the manufacture of cheeses with skim milk to increase contents of the protein and solids, and counteract the high water content of this kind of cheeses.

Hence, the main objective of this paper is the characterization of the volatile profile of the cheese Port Salut Argentino light cheese with MPC, with 34 days of ripening using HS-SPME/GC-MS, in order to determine the compounds that provide its characteristic aroma.

\section{Materials and Methods}

Commercial reduced fat Port Salut Argentino cheeses manufactured at a local factory (SanCor, Sunchales, Santa Fe, Argentina) by rennet coagulation, with addition of milk protein concentrate (MPC), with 34 days of ripening were used. Cheeses were manufactured at the local factory by rennet coagulation, with addition of milk protein concentrate (MPC). Cheeses in a heat-shrinkable plastic packing were 30 $\mathrm{cm}$ square side and $7 \mathrm{~cm}$ in height, were brought to the laboratory on ice bins and stored at $8-10^{\circ} \mathrm{C}$ for study. Samples were taken at the center of cheese after ripening time. Cheese samples were grated and stored a $-12^{\circ} \mathrm{C}$ before use.
Chesses are low-moisture matrix susceptible to primary proteolysis, by rennet and some starter cell liberating proteolytic enzymes, producing soluble nitrogen (SN). The $\mathrm{SN}$ fraction contains peptides and free amino acids, produced by the action of coagulating enzymes that hydrolyze preferentially $\alpha_{\mathrm{S} 1}$-casein rather than $\beta$-casein Samples of low-moisture cheeses studied and reported that SN content in samples are increased during ripening.

Moisture content, total nitrogen (TN) and water-soluble nitrogen (SN) content were determined using reported methods with the same equipment already used for cheese characterization [5].

The initial $\mathrm{pH}$, moisture, fat and total protein contents of cheeses were $5.35,56.08 \pm 0.14 \%, 12.81 \pm 0.09 \%, 25.22 \pm$ $0.39 \%$, respectively. Fat content and $\mathrm{pH}$ remain almost constant over the ripening time. Changes in moisture and total nitrogen (TN) content at different ripening time are shown in Table 1 . The TN content changes significantly between 6 and 34 days. The 4.6-SN content increase, however, did not change statistically during ripening time.

Table 1. Changes of moisture and total nitrogen (TN) contents during ripening.

\begin{tabular}{lll}
\hline $\begin{array}{l}\text { Ripening time } \\
\text { (days) }\end{array}$ & $\begin{array}{l}\text { Moisture content } \\
(\mathbf{\% w} / \mathbf{w})\end{array}$ & $\begin{array}{l}\text { Total nitrogen, TN } \\
(\mathbf{\% w} / \mathbf{w})\end{array}$ \\
\hline 6 & $56.78 \pm 0.82^{\mathrm{b}}$ & $24.48 \pm 0.87^{\mathrm{a}}$ \\
16 & $55.64 \pm 0.43^{\mathrm{b}}$ & $25.75 \pm 0.49^{\mathrm{a}}$ \\
34 & $55.45 \pm 0.94^{\mathrm{b}}$ & $25.03 \pm 0.43^{\mathrm{a}}$ \\
\hline a, b Means values and standard deviations of three replicates. Column with the \\
same superscript letter are not significantly different $(\mathrm{P}<0.05)$.
\end{tabular}

For analysis, a portion of $5 \mathrm{~g}$ of thawed grated cheese was placed in $30 \mathrm{ml}$ glass vial, hermetically sealed with an aluminium seal and butylteflon septa. The vessels were thermostatized at $40^{\circ} \mathrm{C}$ for 20 minutes. During this equilibration time, the transfer of the analytes to the headspace increased. The fiber of $1 \mathrm{~cm}$ x 50/30 $\mu \mathrm{m}$ StableflexDivinylbenzene / Carboxen / Polydimethylsiloxane (DVB/Car/PDMS) (Agilent technologies, Santa Clara, CA, USA) in a SPME holder for manual sampling (Agilent Technologies, Santa Clara, CA, USA) was exposed into the headspace for 30 minutes at $40^{\circ} \mathrm{C}$. Volatile compounds were immediately desorbed from the fiber in the injector port of gas chromatograph, at $250^{\circ} \mathrm{C}$ during 5 minutes.

A GC-MS (Perkin Elmer, Clarus 600T) was used to analyze the cheese headspace volatile components, which were separated using a capillary column (Perkin Elmer, Elite-5, $30 \mathrm{~m}$ x $0.25 \mathrm{~mm}$ ID $\times 0.25 \mu \mathrm{m}$ film thickness). The GC oven temperature was programmed as follows: $40^{\circ} \mathrm{C}$ held for 10 minutes, then increased to $150^{\circ} \mathrm{C}$ at a rate of $6^{\circ} \mathrm{C} /$ minute, then increased to $230^{\circ} \mathrm{C}$ at a rate of $10^{\circ} \mathrm{C} /$ minute and held for 10 minutes. Flow carrier gas, helium, at $1 \mathrm{ml} /$ minute in mode splitless. The MS operated in electron impact mode with electron impact energy of $70 \mathrm{eV}$ and scanning from $40 \mathrm{~m} / \mathrm{z}$ to $500 \mathrm{~m} / \mathrm{z}$. Compounds were identified by comparing the experimental spectra with spectra from NIST 08 (NIST/EPA/NIH Mass Spectral Library, version 2.0, USA) as is shown in Figure 1 for the peak identification presented in Table 2. 


\section{Results and Discussion}

The headspace SPME extraction mode is preferred for volatile compounds because it provides greater selectivity, sensitivity, and rapidity, and an elongated fiber lifetime. Selectivity can be altered by changing the phase type and thickness according to the characteristics of the analytes, a

100

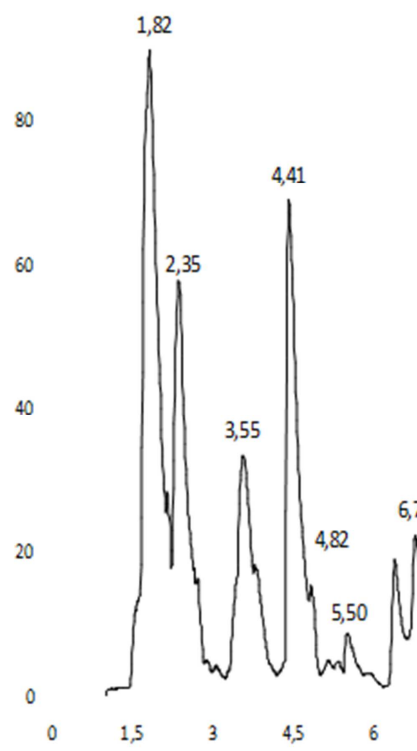

thick phase coat is required to volatile compounds [6].

The headspace SPME extraction and the chromatographic method allowed the determination of 24 volatile compounds (Table 2) in the Port Salut Argentino Light with MPC. A total of: six fatty acids, six ketones, five alcohols, three esters, one aldehyde, two aromatics and one sulphur compounds were defined.

Figure 1. Typical TIC chromatogram of volatile compounds of Port Salut Argentino light cheese with 34 days of ripenning using HS-SPME and CG-MS. For peak identification see Table 2.

\subsection{Free Fatty Acids}

Six free fatty acids (FFAs) are detected. They are important components of cheese flavor, and serve as precursors to methyl ketones, alcohols, lactones, and esters. Their role is quite different depending on the cheese variety [7], but higher concentrations of FFA can cause off-flavours (rancid).

In volatile fraction of Port Salut Argentino light cheese, even-numbered $\left(\mathrm{C}_{4}-\mathrm{C}_{12}\right)$ carbon atoms saturated fatty acids were found: butanoic, hexanoic, octanoic and decanoic, with they have characteristic notes (vinegar, pungent, rancid). Odd numbered linear-chain FFAs such as acetic and propanoic were found, and they represented a minority fraction. Short and medium-chains FFA, because their low aroma thresholds, are considered to be important contributors to the flavor profile in a wide variety of cheeses. Excessive concentrations of FFA may cause rancid flavor [8].

Fatty acids may originate from lipolysis, mainly due to the activity of pregastric esterase present in the rennet and also, in part, to the activity of lipo-protein lipase of raw milk [9]. According their results, the lipase responsible for FFA production is more likely to originate from the milk itself than from the lactic acid bacteria since the milk fat must be partially hydrolysed before the starter culture lipases become effective. Another evidence of predomination of endogenous lipase activities is the fact that milk lipase is specific for the $\alpha$-position on the glycerol backbone of triglyceride molecule.
A lower proportion of short-chain originates from the degradation of lactose and amino acids, and they can also be derived from ketones, esters, and aldehydes by oxidation [10].

FFAs can also result of the metabolism of lactose, be biosynthesized directly from acetyl-CoA, or formed from amino acid conversion (for example, valine and leucine) [11]. FFAs have an important contribution to cheese aroma, either directly by their aromatic notes, or as precursors of carbonyl compounds, alcohols, alkanes and esters [4].

Acetic acid originates from a number of processes including the oxidation of lactose by lactic acid bacteria under anaerobic conditions, and the catabolism (oxidative deamination and decarboxilation) of alanine and serine by lactic acid bacteria. Propanoic acid originates mainly from metabolism of lactate by Propionibacterium sp.

According most of the studies, butanoic acid can be produced by lipolysis, fermentation of glucose or lactate (e.g. Clostridium tyrobutyricum), and the breakdown of some amino acids [9]. Generally, butanoic acid has a major aroma impact compound with its characteristic cheesy sharp aroma [12] and plays an important role in the flavour of many cheese types. However, large amounts of this volatile acid, which may originate, are undesirable [10].

Hexanoic acid is primarily derived from milk lipolysis, and was perceived as a very mild to strong sharp, goat-like smell [10]. Results were describing the lack of intense goat-like aroma in Cheddar cheese with high concentrations of octanoic acid. 
Table 2. Volatile compounds identified in Port Salut Argentino light cheese with 34 days of ripening (PSA 34) by HS-SPME and CG-MS, according NIST database.

\begin{tabular}{|c|c|c|c|}
\hline Compound & Flavour note $^{\mathrm{A}}$ & PSA 34 $t_{r}{ }^{B}$ & TIC/ion $^{\mathrm{C}}$ \\
\hline Acetic acid & vinegar, pungent & 2,35 & TIC \\
\hline Propanoic acid & vinegar, pungent & 3,76 & 74 \\
\hline Butanoic acid & rancid, cheesy, putrid, sweaty & 8,06 & TIC \\
\hline Hexanoic acid & pungent, blue cheese, goat-like & 17,25 & TIC \\
\hline Octanoic acid & goaty, waxy, sopay, body odour & 22,50 & TIC \\
\hline Decanoic acid & rancid & 26,91 & TIC \\
\hline Acetone & Ethereal, powerful, fruity & 1,84 & 58 \\
\hline 2-butanone & Acetone, etheric & 2,77 & 72 \\
\hline 2-pentanone & Fruity, acetone, sweet, ethereal & 3,42 & 86 \\
\hline 3-hydroxy-2-butanone & Buttery & 3,82 & 88 \\
\hline 2-heptanone & Floral, fruity & 12,34 & TIC \\
\hline 2-nonanone & Musty, fruity, floral & 3,06 & TIC \\
\hline Ethanol & Alcohol, mild & 1,75 & 45 \\
\hline 1-butanol & Sweet, fruity & 3,06 & 56 \\
\hline 3-methyl-1-butanol & Fruity, alcohol & 4,41 & 55 \\
\hline 1-hexanol & & 11,28 & TIC \\
\hline 2-heptanol & Earthy oil & 13,00 & 98 \\
\hline Ethyl butanoate & Pineapple, sweet, banana & 6,76 & TIC \\
\hline Ethyl hexanoate & Pineapple, apple powerful & 17,15 & TIC \\
\hline Ethyl octanoate & Apricot, win, floral & 22,89 & TIC \\
\hline Toluene & & 5,17 & 91 \\
\hline Benzaldehyde & & 15,48 & $77 / 106$ \\
\hline Heptanal & & 12,85 & 96 \\
\hline Dimethyl disulphide & & 4,57 & 94 \\
\hline
\end{tabular}

${ }^{\text {A }}$ Sensory properties of the most characteristics compounds are indicated [4].

${ }^{B}$ Retention time (minutes)

${ }^{\mathrm{C}}$ When the resolution was not perfect, retention times and the consequent compound identification, was realized from the spectra from the specified ions, and not from the ion current (TIC).

\subsection{Ketones}

A total of six ketones were identified in Port Salut Argentino light cheese. The majority were methylketones: 2-butanone, 2-pentanone, 2-heptanone, 2-nonanone and 2-undecanone, in addition to acetone and 3-hydroxy-2-butanone.

Ketones are common constituents of most dairy products, and are considered as an important fraction of volatile profile, which may be reduced to secondary alcohols [13]. They have typical odours (fruity, floral, mushroom, or musty notes) and low perception thresholds [14].

Methylketones are derived from FFA by $\beta$-oxidation pathway mechanism [2], [15], or from $\beta$-ketoacids, which are decarboxylated to corresponding methyl ketones with one carbon atom less, mainly from $\mathrm{C}_{6: 0}$ to $\mathrm{C}_{12: 0}$ fatty acids. However, it has also been suggested that high concentrations of methyl ketones in non mold-ripened cheeses may be an indication of mold contamination [8].

On the other hand, 3-hidroxi-2-butanone (acetoin), with buttery aroma, is produced as a consequence of lactococcal lactose and citrate metabolism, but it can be also produced from aspartic acid. The 3-hydroxy-2-butanone can be derived from diacetyl metabolism; or alternatively, from the $\alpha$-acetolactate, formed from the reaction of pyruvate and acetaldehyde-TPP, which is very unstable and could be decarboxylated non-oxidatively to form acetoin, or oxidatively to form diacetyl [13]. Reduction of acetoin by enzymes from bacteria present in raw milk [2] results in formation 2-butanone and 2-butanol.

\subsection{Alcohols}

Five alcohols were identified in Port Salut Argentino light cheese with MPC: ethanol, butanol, hexanol, 2-heptanol, and 3-methylbutanol. Alcohols contribute to the formation of esters, but it, even at high levels, have a limited role in the aroma of cheese.

Ethanol is produced by fermentation of lactose or citrate or from alanine catabolism [2] or from reduction of acetaldehyde [15], and it has been described as an important flavor component in a great diversity of cheeses. It is present in fresh milk and is a volatile product of the lactic fermentation with acetaldehyde, diacetyl, and acetoin [2]. Ethanol has been associated with mild alcohol flavor. Also, may act as a precursor of the ethyl esters formation, via reaction with free fatty acids.

Aliphatic primary alcohols such as butanol and hexanol contribute fruity and nutty notes to the flavor of cheese. Primary alcohols are considered to originate from the corresponding aldehydes produced from fatty acid and amino acid metabolism [2], and in certain cheeses high levels of them can cause flavor defects.

On the other hand, secondary alcohols are formed by oxidoreductase enzyme reduction of methyl ketones; [16] and [8]. They have similar but heavier flavor notes than methyl ketones.

Methyl-branched primary alcohols such as 3-methylbutanol come from reduction of 3-methylbutanal, that can be found in raw milk cheeses with intense proteolysis, formed via Strecker degradation from leucine [4] and [15]. In a wide variety of 
cheeses, 3-methylbutanol is considered an important contributor to overall flavor. Slightly sweet, fresh flavor of many soft cheeses has been attributed to 3-methylbutanol [15].

\subsection{Esters}

The esters identified in Port Salut Argentino light cheese with MPC were are four. They are ethyl esters from the corresponding fatty acids: ethyl butanoate, ethyl hexanoate, ethyloctanoate and ethyl decanoate.

Esters are mainly produced by enzymatic or chemical reaction of fatty acids with primary alcohols and the alcohol concentration is usually the limiting factor in ester production; moreover they can also be formed by transesterification of partial glycerides [3]. Most esters in cheeses are described as having sweet, fruity, and floral notes, and may contribute to cheese aroma by minimizing the sharpness and bitterness imparted by fatty acids and amines, respectively; [4]. Some esters have very low perception thresholds and their contribution heightened by synergistic effect [13].

Different authors have remarked the majority presence of ethyl esters of even-number fatty acids (from $\mathrm{C}_{2}$ to $\mathrm{C}_{16}$ ) in parmigiano reggiano cheeses, being ethyl acetate, ethyl butanoate, ethyl hexanoate and ethyl octanoate, the most abundant [2] and [15].

\subsection{Aldehyde}

Only one aldehyde was found into the volatile compounds, heptanal, which was associated with soapy flavor. Aldehydes are likely to have an important impact on the aroma of investigated cheese due to their low aroma threshold values. They are characterized by green-grass or herbaceous aroma and can be very unpleasant when their concentrations exceed certain values.

Aliphatic aldehydes are the main products of autoxidation of unsaturated fatty acids: autoxidation proceeds via hydroperoxides, which in turn undergoes further degradation to hydrocarbons, alcohols and carbonyl compounds [2]; or from amino acids by Strecker degradation [4]. Aldehydes are transitory compounds in cheese because they are rapidly reduced to primary alcohols or oxidized to the corresponding acids [12].

The low level of aldehydes compared to other volatile compounds could indicate an optimal maturation of cheeses.

\subsection{Aromatic Compounds}

Two aromatic compounds were identified in our study: benzaldehyde and toluene.

Potential precursors of benzaldehyde are the aromatic amino acids phenylalanine and tyrosine. Benzaldehyde may be produced from the $\alpha$-oxidation of phenylacetaldehyde, which is derived, via Strecker reaction, from phenylalanine; or from $\beta$-oxidation of cinnamic acid. This compound possesses an aromatic note of bitter almond [12] or sweet note.

Toluene was considered in some cases to be significantly influenced by strains of Lactococcus lactis. The origin of aromatic hydrocarbons (such as benzene, toluene, xylenes, and ethyl benzenes) and halogenated hydrocarbons (chloroform, dichloromethane, and others) in dairy products has not been satisfactorily explained, although they have been found in milk and cheeses [13].

\subsection{Sulphur Compounds}

In Port Salut Argentino light cheese was identified one sulphur compound: dimethyl disulphide. Sulphur compound originate from methionine and cysteine degradation, and result from cleavage of a bond between carbon and sulphur by a methionine-demethiolase. These components are described as having strong garlic, onion, or very ripe cheese odours [4].

Dimethylsulphide (DMS), DMDS and DMTS are thought to be important contributors to cheese flavour. DMS is a product of the metabolism of propionic acid bacteria and is formed from methionine. It was listed as a main odorant of Camembert and Cheddar (regular and low fat) cheese types. In 8 and 12 months ripened Ragusano cheese the other S-compound, DMDS seems to become more important, while DMTS contributes significantly to the aroma of Gruyere cheese. DMTS is generally associated with odour notes of cooked cabbage, broccoli or cauli flower [10].

Sulphur compounds are thought to interact with each other and with other compounds in cheese, generating other volatile flavour compounds.

\section{Conclusion}

The study of the volatile profile of Port Salut Argentino light cheese with MPC showed that fatty acids and ketones were the most abundant compounds presents, being the butanoic acid and the 2-heptanone the most abundant. The following are the alcohols, being the 3-methyl-2-butanol the most important.

The esters of the even-numbered fatty acids, the aromatics, the aldehyde and the sulphur compound were low respect to the others compounds.

This research provides a first and partial characterization of the volatile profile of Port Salut Argentino light cheese with MPC. However, a correlation between the nature of the volatile compounds, sensory characteristics and ripening time, with the texture, it will be possible in further studies to define the optimal conditions to obtain the better acceptance of the consumer.

\section{Acknowledgements}

This study was conducted with the financial support of Universidad Nacional del Litoral (Santa Fe, Argentina), Consejo Nacional de Investigaciones Científicas y Técnicas (Argentina), and Agencia Nacional de Promoción Científica y Tecnológica (Argentina). The authors acknowledge SanCor Cooperativas Unidas Ltd. (Santa Fe, Argentina) for the supply of cheeses and the special cheese elaboration for this study. The authors acknowledge Juan Carlos Andini for technical assistance in the HS-SPME/GC-MS analysis and the peak identification. 


\section{References}

[1] F. Delgado, J. González-Crespo, R. Cava, J. García-Parra and R. Ramírez, "Characterization by SPME-GC-MS of the volatile profile of a Spanish soft cheese P. D. O. Torta del Casar during ripening”. Food Chemistry, vol. 118, 2010, pp.182-189.

[2] G. Barbieri, L. Bolzoni, M. Careri, J. Mangia, G. Parolari, S. Spagnoli and R. Virgili. "Study of the Volatile Fraction of Parmesan Cheese". J of Agricultural and Food Chemistry, vol. 42, 1994, pp. 1170-1176.

[3] R. Holland, S. Liu, V. Crow, M. Delabre, M. Lubbers, M. Bennett and G. Norris. "Esterases of lactic acid bacteria and cheese flavour: Milk fat hydrolysis, alcoholysis and esterification". International Dairy Journal, vol. 15, 2005, pp. 711-718.

[4] I. Ferreira, O. Pinho and P. Sampaio. "Volatile fraction of DOP Castelo Branco cheese: Influence of breed". Food Chemistry, vol. 112, 2009, pp. 1053-1059.

[5] I. Alberini, M. Miccolo and A. Rubiolo. "Textural and chemical changes during ripening of Port Salut Argentino light cheese with milk protein concentrate after long frozen storage period" J Food Processing and Preservation, vol. 65 (1), 2015, pp. $45-51$.

[6] E. Vítová, B. Loupancová, J. Zemanová, H. Štoudková, P. Březina and L. Babák. "Solid-Phase Microextraction for Analysis of Mould Cheese Aroma". Czech Journal of Food Sciences, vol. 24(6), 2006, pp. 268-274.

[7] M. Ziino, C. Condurso, V. Romeo, D. Giuffrida, and A. Verzera "Characterization of Provola dei Nebrodi, a typical Sicilian cheese, by volatiles analysis using SPME-GC/MS". International Dairy Journal, vol. 15, 2005, pp. 585-593.

[8] M. Corrëa Lelles Nogueira, G. Lubachevsky and S. Rankin. "A study of the volatile composition of Minas cheese". LWT-Food Science and Technology, vol. 38, 2005, pp. 555-563.
[9] Y. Collins, P. McSweeney and M. Wilkinson, "Lipolysis and free fatty acid catabolism in cheese: A review of current knowledge". International Dairy Journal, vol. 13, 2003, pp. 841-866.

[10] P. Curioni and J. Bosset. "Review Key odorants in various cheese types as determined by gas chromatography-olfactometry". International Dairy Journal, vol. 12, 2002, pp. 959-984.

[11] F. Tavaria, A. Silva Ferreira and F. Malcata. "Volatile free fatty acids as ripening indicators for Serra da Estrela Cheese". Journal Dairy Science, vol. 87, 2004, pp. 4064-4072.

[12] D. Frank, C. Owen and J. Patterson. "Solid phase microextraction (SPME) combined with gas-chromatography and olfactometry-mass spectrometry for characterization of cheese aroma compounds". LWT-Food Science and Technology, vol. 37, 2004, pp. 139-154.

[13] M. Carbonell, M. Nuñez and E. Fernandez-Garcia. "Evolution of the volatile components of ewe raw milk La Serena cheese during ripening. Correlation with flavour characteristics". Le Lait, vol. 82, 2002, pp. 683-698.

[14] M. Qian, C. Nelson and S. Bloomer. "Evaluation of Fat-Derived Aroma Compounds in Blue Cheese by Dynamic Headspace GC/Olfactometry-MS". Journal of the American Oil Chemists Society, vol. 79 (7), 2002, pp. 663-667.

[15] McSweeney and M. Sousa. "Biochemical pathways for the production of flavor compounds in cheeses during ripening: A review". Le Lait-Dairy Science and Technology, vol. 80, 2000, pp. 293-324.

[16] P. Molimard and H. Spinnler. "Review: compounds involved in the flavour of surface mold-ripened cheeses: origins and properties". Journal of Dairy Science, vol. 79, 1996, pp. $169-184$. 